\title{
Ultrasonography of the Anterior Segment
}

\author{
Martin Heur, MD, PhD and Bennie H. Jeng, MD
}

\section{Introduction}

Most of the anterior segment structures can be evaluated with slit lamp biomicroscopy because of corneal transparency. The cornea is the main refractive element of the eye, accounting for two-thirds of the total refractive power. Because of this function, there are many mechanisms through which the cornea maintains its transparency, including ultrastructural arrangement of its collagen lamellae, maintenance of avascularity, and endothelial pump function for deturgesence. The cornea is routinely examined by slit lamp biomicroscopy because of its transparency, and therefore it is not routinely evaluated with ultrasound. However, there are some situations in which the cornea loses its transparency, and the ultrasound becomes an important adjunct in the evaluation of the anterior segment. In situations requiring ultrasound evaluation of the anterior segment, because of the limitations of B-scan ultrasonography, ultrasound biomicroscopy (UBM), due to its high resolution, is the preferred modality. ${ }^{1}$ This chapter will review UBM evaluation of the cornea, intraocular lenses, and anterior segment trauma.

\section{Evaluation of the Cornea}

There are numerous conditions that can result in the loss of corneal transparency, including congenital corneal opacification, corneal lesions, and corneal dystrophies.

\section{A. Congenital corneal opacification}

UBM can be an important adjunct in the evaluation of a patient with congenital corneal opacification with regards to imaging the cornea and the rest of the anterior segment. In a report of 22 eyes in 13 patients who were diagnosed with Peter's anomaly, corneal dystrophy, and sclerocornea, UBM findings changed the final diagnosis in 5 of the 13 cases (Figure 1). ${ }^{2}$ Interestingly, the hypoechoic region in the anterior stroma on UBM correlated with absence of Bowman's layer on histology. ${ }^{2}$ The authors also noted that UBM revealed aniridia in one patient and congenital aphakia in another that was not apparent clinically. ${ }^{2}$ In another case, UBM images also correlated well with histopathologic analysis in an infant with sclerocornea. ${ }^{3}$ UBM can also aid in the diagnosis of long-standing corneal opacification in adults, as demonstrated by a case a 35-year-old diagnosed with Peter's anomaly: UBM imaging demonstrated diffuse iridocorneal adhesions, shallow anterior chamber, and abnormal hyperechoicity of the posterior corneal surface, thereby facilitating the diagnosis in the patient.

${ }^{4}$ In the above cases, UBM was useful not only in the initial evaluation, but also in providing guidance for surgical management of the patients by providing images of other anterior segment structures such as the lens and the iridocorneal angle.

Correspondence to: Bennie H. Jeng, M.D., Cole Eye Institute, Cleveland Clinic, 9500 Euclid Ave, i-32, Cleveland, OH 44195, Telephone: (216) 445-9519, Fax: (216) 445-2226, jengb@ccf.org.

Publisher's Disclaimer: This is a PDF file of an unedited manuscript that has been accepted for publication. As a service to our customers we are providing this early version of the manuscript. The manuscript will undergo copyediting, typesetting, and review of the resulting proof before it is published in its final citable form. Please note that during the production process errors may be discovered which could affect the content, and all legal disclaimers that apply to the journal pertain. 


\section{B. Corneal lesions}

Although the depth of corneal lesions can usually be directly visualized by slit lamp biomicroscopy, UBM can be useful in instances when the extent of the lesion cannot be fully visualized (Figure 2). In a patient with a progressively enlarging corneal mass, UBM showed the mass to be well-demarcated from the underlying corneal tissue, and thereby allowed for appropriate surgical planning. The excised mass was shown to be consistent with a keloid on histopathology. ${ }^{5}$

However, other investigators found that in a case series of 8 patients with limbal dermoids, one patient had a full thickness dermoid and that Descemet's membrane could not be visualized in the other cases because of attenuation of the sound waves. ${ }^{6}$ They reported that the depth of the corneal involvement by the dermoids were difficult to ascertain by UBM due to sound wave attenuation by the lesion, demonstrating a weakness of UBM in evaluating such corneal lesions. This weakness was also noted in another report where UBM was not effective in measuring the depth of corneal lesions in patients with anterior stromal dystrophies undergoing evaluation for phototherapeutic keratectomy. ${ }^{7}$

\section{Corneal dystrophies}

Corneal dystrophies are typically diagnosed clinically based on the specific layer of the cornea affected and characteristic appearances on slit-lamp biomicroscopy. A report of posterior amorphous corneal dystrophy, an autosomal dominant disorder characterized by bilateral diffuse, showed sheet-like opacities of the posterior stroma accompanied by corneal thinning.

${ }^{8}$ UBM showed that the opacities were located deep within the stroma. ${ }^{9}$ UBM of granular dystrophy showed highly reflective hyaline granules in the superficial stroma (Figure 3 ). ${ }^{10}$

\section{Refractive surgery}

An arc-scanning very high frequency (VHF) ultrasound has been developed that combines parallel B-scans with digital signal processing to provide 3 dimensional mapping of the cornea. ${ }^{11}$ The arc-scanning path keeps the transducer perpendicular to the corneal surface and allows fine imaging of corneal layers. This modality is useful in refractive surgery because of its ability to generate elevation maps of anterior and posterior corneal surfaces along with a pachymetry map.

\section{Evaluation of Intraocular Lenses}

Because of the many advantages of placing an intraocular lens (IOL) in the capsular bag, such as decreased frequency of uveitis, hyphema, and IOL dislocation, it has become the preferred location for IOL placement. However, there are some instances when either the lens cannot be placed in the bag or the haptics are inadvertently malpositioned.

\section{A. Posterior chamber intraocular lenses}

Recurrent iritis with pigment dispersion or recurrent hyphema occurring after cataract surgery can be a sign of iris-ciliary irritation resulting from haptic contact where UBM can be a useful adjunct in the evaluation. ${ }^{12-14}$ Malpositioned posterior chamber IOL's can also cause IOL tilt that can be difficult to appreciate on slit lamp biomicroscopy (Figures 4 and 5). UBM can also be used to determine the precise position of the scleral-fixated IOL haptics relative to the ciliary sulcus. ${ }^{15-17}$

\section{B. Anterior chamber intraocular lenses (ACIOL)}

UBM can be used in cases of ACIOL malpositioning, to visualize the precise location of the haptics in relation to the surrounding structures such as the iris and iridocorneal angle, and the 
ciliary body. ${ }^{18}$ Although ACIOL haptics can normally be observed by gonioscopy, hyphema and corneal edema due to malpositioned ACIOL haptics may preclude its visualization as well as that of the rest of the anterior segment structures. Corneal decompensation secondary to malpositioned ACIOL haptics can progress to the point of requiring a corneal transplanr. In those patients, UBM can be used to determine the depth of adhesions over implant haptics and predict the ease of removal. ${ }^{19}$

\section{Phakic intraocular lenses}

UBM is also becoming an important adjunct in preoperative and postoperative examinations of patients undergoing evaluation for phakic IOL placement for correction of high myopia. Preoperatively, UBM can be used to determine anterior chamber depth. Postoperatively, the position of the phakic IOL haptics as well as the distances from corneal endothelium to phakic IOL and from phakic IOL to crystalline lens can also be evaluated. ${ }^{20-25}$

\section{Evaluation of Anterior Segment Trauma}

Trauma to the anterior segment can result in corneal edema and hyphema, precluding a view of the other structures in the anterior segment, creating a situation where UBM becomes a useful adjunct in the evaluation.

\section{A. Iridocorneal angle trauma}

UBM can be used to visualize the iridocorneal angle structures and the ciliary body, allowing for differentiation between iridodialysis, angle recession and cyclodialysis in cases of trauma. Iridodialysis occurs when the iris is torn completely at its root, and this may be difficult to appreciate in the presence of media opacities (Figure 6). Separation between the muscular layers of the ciliary body results in angle recession, causing in a widening of the iridocorneal angle on gonioscopy. Detachment of the ciliary body from the scleral spur results in cyclodialysis, allowing for communication between the anterior chamber and the supraciliary space (Figure 7). UBM is of particular importance in the diagnosis and evaluation of cyclodialysis clefts, even in the presence of a closed angle, allowing for determination of the extent of dialysis and enhancement of the surgical plan. ${ }^{26}$ UBM can be readily used to differentiate between iridodialysis, angle recession, and cyclodialysis even in the presence of media opacities. ${ }^{27,} 28$

\section{B. Foreign body}

UBM can be useful in detection of a foreign body following penetrating injuries that may be complicated by media opacities, small foreign body size, or concealed locations such as in the iridocorneal angle or behind the iris. ${ }^{29}$ Foreign bodies are readily localized by UBM, and they generate characteristic acoustic artifacts on ultrasonography based on their composition: those foreign bodies containing pockets of air, such as wood and concrete, create shadowing due to dampening of the sound waves by air, while those that are dense, such as metal and glass, create reflective tails due to internal reflection of the sound waves (Figure 8). ${ }^{30}$

\section{Surgical planning}

UBM can be helpful in the planning of cataract surgeries in eyes that have sustained trauma. In an eye with traumatic cataract due to a penetrating injury, the integrity of the posterior capsule may be difficult to ascertain using slit lamp biomicroscopy. UBM can be used to image the posterior capsule in the presence of a cataract precluding a slit lamp view to help with surgical planning. ${ }^{31}$ In addition, eyes that have sustained blunt trauma may have occult zonular injury that may not be apparent on slit lamp biomicroscopy. Preoperative diagnosis of occult 
zonular injury by UBM imaging may be of benefit in reducing intraoperative complications during cataract surgery (Figure 9). ${ }^{32}$

\section{Descemet's membrane detachment}

UBM can also be a useful adjunct in diagnosing and repairing large Descemet's membrane detachments. In addition to visualizing the membrane, UBM imaging can also verify correct suture placement and membrane repositioning during the repair (Figure 10). ${ }^{33,} 34$

\section{Summary}

Although the anterior segment is not routinely evaluated by ultrasound due to corneal transparency, there are instances where the cornea loses its transparency and UBM becomes a useful adjunct in the diagnostic evaluation of the anterior segment. In addition, UBM can be helpful in the formulation of surgical or medical management plans for patients with opacified corneas. UBM is useful in the evaluation of IOL haptic positioning in pseudophakic patients and in the evaluation of phakic IOL patients. Finally, UBM can also be useful in the evaluation of eyes that have sustained trauma by allowing for imaging of the anterior segment structures even in the presence of media opacities.

\section{References}

1. LeMay M. B-scan ultrasonography of the anterior segment of the eye. Br J Ophthalmol 1978;62(9): 651-6. [PubMed: 708681]

2. Nischal KK, Naor J, Jay V, et al. Clinicopathological correlation of congenital corneal opacification using ultrasound biomicroscopy. Br J Ophthalmol 2002;86(1):62-9. [PubMed: 11801506]

3. Kim T, Cohen EJ, Schnall BM, et al. Ultrasound biomicroscopy and histopathology of sclerocornea. Cornea 1998;17(4):443-5. [PubMed: 9676919]

4. Haddad AM, Greenfield DS, Stegman Z, et al. Peter's anomaly: diagnosis by ultrasound biomicroscopy. Ophthalmic Surg Lasers 1997;28(4):311-2. [PubMed: 9101570]

5. Chawla B, Agarwal A, Kashyap S, Tandon R. Diagnosis and management of corneal keloid. Clin Experiment Ophthalmol 2007;35(9):855-7. [PubMed: 18173415]

6. Hoops JP, Ludwig K, Boergen KP, Kampik A. Preoperative evaluation of limbal dermoids using highresolution biomicroscopy. Graefes Arch Clin Exp Ophthalmol 2001;239(6):459-61. [PubMed: 11561796]

7. Rapuano CJ. Excimer laser phototherapeutic keratectomy in eyes with anterior corneal dystrophies: short-term clinical outcomes with and without an antihyperopia treatment and poor effectiveness of ultrasound biomicroscopic evaluation. Cornea 2005;24(1):20-31. [PubMed: 15604863]

8. Carpel EF, Sigelman RJ, Doughman DJ. Posterior amorphous corneal dystrophy. Am J Ophthalmol 1977;83(5):629-32. [PubMed: 301356]

9. Castelo Branco B, Chalita MR, Casanova FH, et al. Posterior amorphous corneal dystrophy: ultrasound biomicroscopy findings in two cases. Cornea 2002;21(2):220-2. [PubMed: 11862100]

10. Pavlin, CJ.; Foster, FS. High Resolution Ultrasound. In: Krachmer, JH.; Mannis, MJ.; Holland, EJ., editors. Conrea. St. Louis: Mosby; 2004.

11. Reinstein DZ, Silverman RH, Raevsky T, et al. Arc-scanning very high-frequency digital ultrasound for 3D pachymetric mapping of the corneal epithelium and stroma in laser in situ keratomileusis. $\mathrm{J}$ Refract Surg 2000;16(4):414-30. [PubMed: 10939721]

12. LeBoyer RM, Werner L, Snyder ME, et al. Acute haptic-induced ciliary sulcus irritation associated with single-piece AcrySof intraocular lenses. J Cataract Refract Surg 2005;31(7):1421-7. [PubMed: 16105617]

13. Ozdal PC, Mansour M, Deschenes J. Ultrasound biomicroscopy of pseudophakic eyes with chronic postoperative inflammation. J Cataract Refract Surg 2003;29(6):1185-91. [PubMed: 12842688] 
14. Pavlin CJ, Harasiewicz K, Foster FS. Ultrasound biomicroscopic analysis of haptic position in lateonset, recurrent hyphema after posterior chamber lens implantation. J Cataract Refract Surg 1994;20 (2):182-5. [PubMed: 8201571]

15. Manabe $\mathrm{S}, \mathrm{Oh} \mathrm{H}$, Amino K, et al. Ultrasound biomicroscopic analysis of posterior chamber intraocular lenses with transscleral sulcus suture. Ophthalmology 2000;107(12):2172-8. [PubMed: 11097591]

16. Pavlin CJ, Rootman D, Arshinoff S, et al. Determination of haptic position of transsclerally fixated posterior chamber intraocular lenses by ultrasound biomicroscopy. J Cataract Refract Surg 1993;19 (5):573-7. [PubMed: 8229709]

17. Sewelam A, Ismail AM, El Serogy H. Ultrasound biomicroscopy of haptic position after transscleral fixation of posterior chamber intraocular lenses. J Cataract Refract Surg 2001;27(9):1418-22. [PubMed: 11566525]

18. Anton A, Weinreb RN. Recurrent hyphema secondary to anterior chamber lens implant. Surv Ophthalmol 1997;41(5):414-6. [PubMed: 9163839]

19. Rutnin SS, Pavlin CJ, Slomovic AR, et al. Preoperative ultrasound biomicroscopy to assess ease of haptic removal before penetrating keratoplasty combined with lens exchange. J Cataract Refract Surg 1997;23(2):239-43. [PubMed: 9113575]

20. de Souza RF, Allemann N, Forseto A, et al. Ultrasound biomicroscopy and Scheimpflug photography of angle-supported phakic intraocular lens for high myopia. J Cataract Refract Surg 2003;29(6):1159_ 66. [PubMed: 12842684]

21. Garcia-Feijoo J, Alfaro IJ, Cuina-Sardina R, et al. Ultrasound biomicroscopy examination of posterior chamber phakic intraocular lens position. Ophthalmology 2003;110(1):163-72. [PubMed: 12511362]

22. Jimenez-Alfaro I, Garcia-Feijoo J, Perez-Santonja JJ, Cuina R. Ultrasound biomicroscopy of ZSAL-4 anterior chamber phakic intraocular lens for high myopia. J Cataract Refract Surg 2001;27(10):156773. [PubMed: 11687353]

23. Pop M, Payette Y, Mansour M. Ultrasound biomicroscopy of the Artisan phakic intraocular lens in hyperopic eyes. J Cataract Refract Surg 2002;28(10):1799-803. [PubMed: 12388031]

24. Trindade F, Pereira F, Cronemberger S. Ultrasound biomicroscopic imaging of posterior chamber phakic intraocular lens. J Refract Surg 1998;14(5):497-503. [PubMed: 9791815]

25. Yu AY, Lin ZD, Chen XQ, et al. Position of myopic iris-claw phakic intraocular lens by Scheimpflug photography and ultrasound biomicroscopy. Eye 2008;22(2):233-9. [PubMed: 17435684]

26. Gentile RC, Pavlin CJ, Liebmann JM, et al. Diagnosis of traumatic cyclodialysis by ultrasound biomicroscopy. Ophthalmic Surg Lasers 1996;27(2):97-105. [PubMed: 8640444]

27. Berinstein DM, Gentile RC, Sidoti PA, et al. Ultrasound biomicroscopy in anterior ocular trauma. Ophthalmic Surg Lasers 1997;28(3):201-7. [PubMed: 9076793]

28. Ozdal MP, Mansour M, Deschenes J. Ultrasound biomicroscopic evaluation of the traumatized eyes. Eye 2003;17(4):467-72. [PubMed: 12802344]

29. Deramo VA, Shah GK, Baumal CR, et al. Ultrasound biomicroscopy as a tool for detecting and localizing occult foreign bodies after ocular trauma. Ophthalmology 1999;106(2):301-5. [PubMed: 9951481]

30. Laroche D, Ishikawa H, Greenfield D, et al. Ultrasound biomicroscopic localization and evaluation of intraocular foreign bodies. Acta Ophthalmol Scand 1998;76(4):491-5. [PubMed: 9716340]

31. Nguyen TN, Mansour M, Deschenes J, Lindley S. Visualization of posterior lens capsule integrity by $20-\mathrm{MHz}$ ultrasound probe in ocular trauma. Am J Ophthalmol 2003;136(4):754-5. [PubMed: 14516827]

32. McWhae JA, Crichton AC, Rinke M. Ultrasound biomicroscopy for the assessment of zonules after ocular trauma. Ophthalmology 2003;110(7):1340-3. [PubMed: 12867388]

33. Morinelli EN, Najac RD, Speaker MG, et al. Repair of Descemet's membrane detachment with the assistance of intraoperative ultrasound biomicroscopy. Am J Ophthalmol 1996;121(6):718-20. [PubMed: 8644821]

34. Jeng BH, Meisler DM. A combined technique for surgical repair of Descemet's membrane detachments. Ophthalmic Surg Lasers Imaging 2006;37(4):291-7. [PubMed: 16898389] 


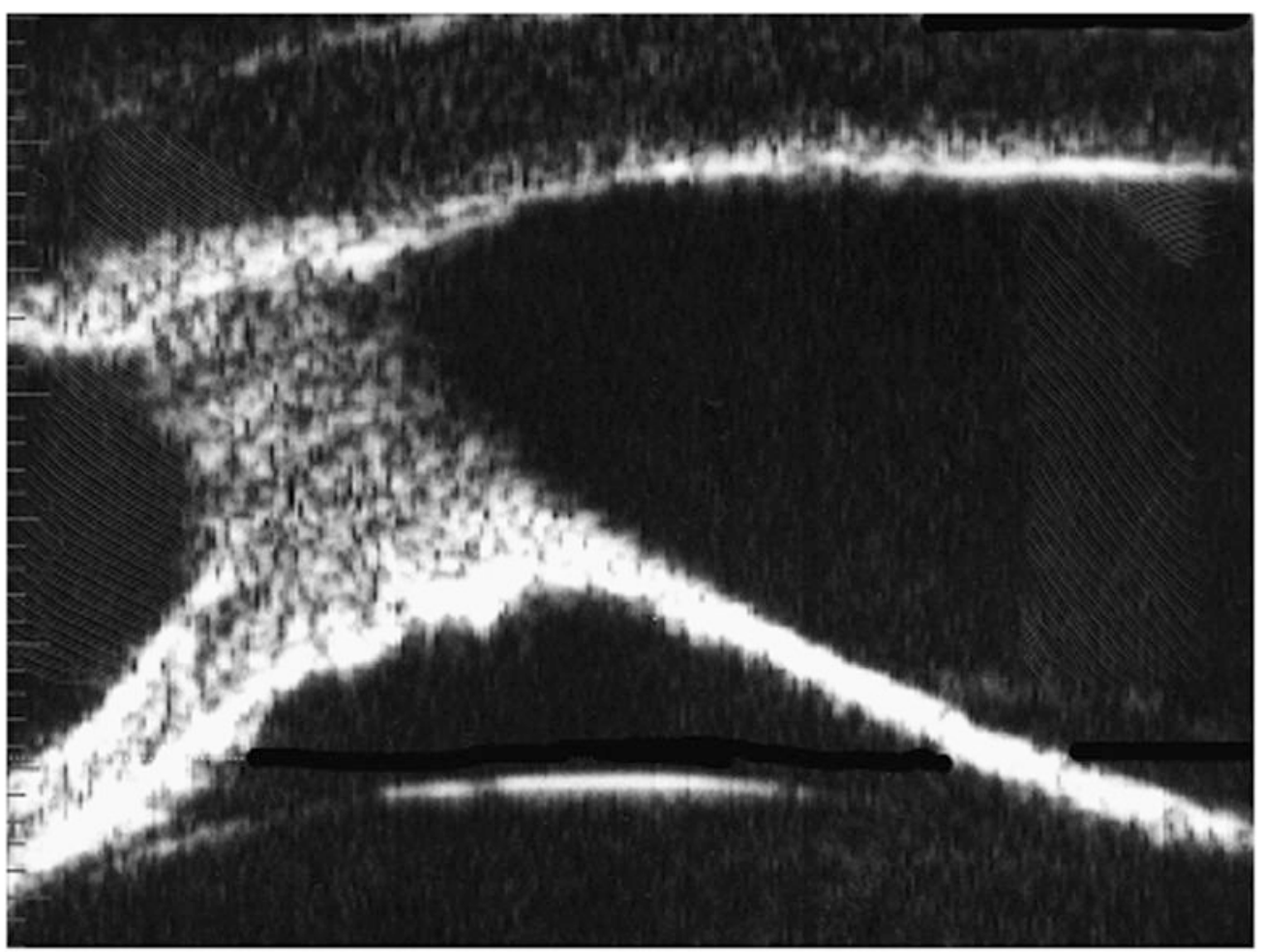

Figure 1.

Peter's anomaly. Note abnormal irido-corneal adhesions. 


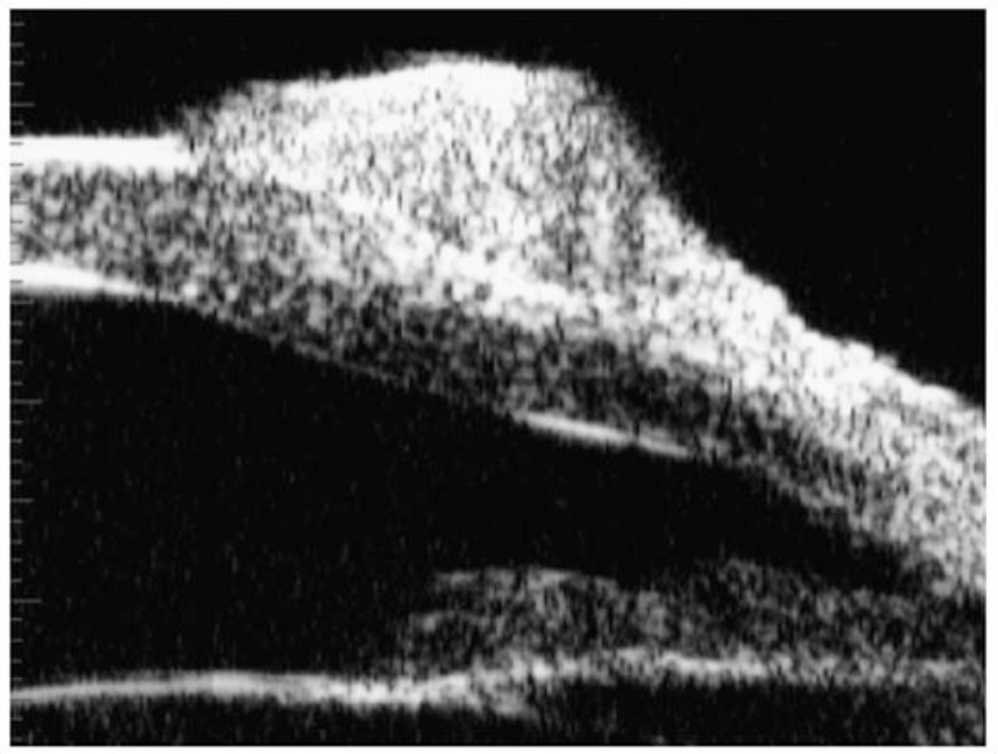

Figure 2.

Corneal lesion. Radial scan shows a dome shaped lesion infiltrating deep into the cornea. 


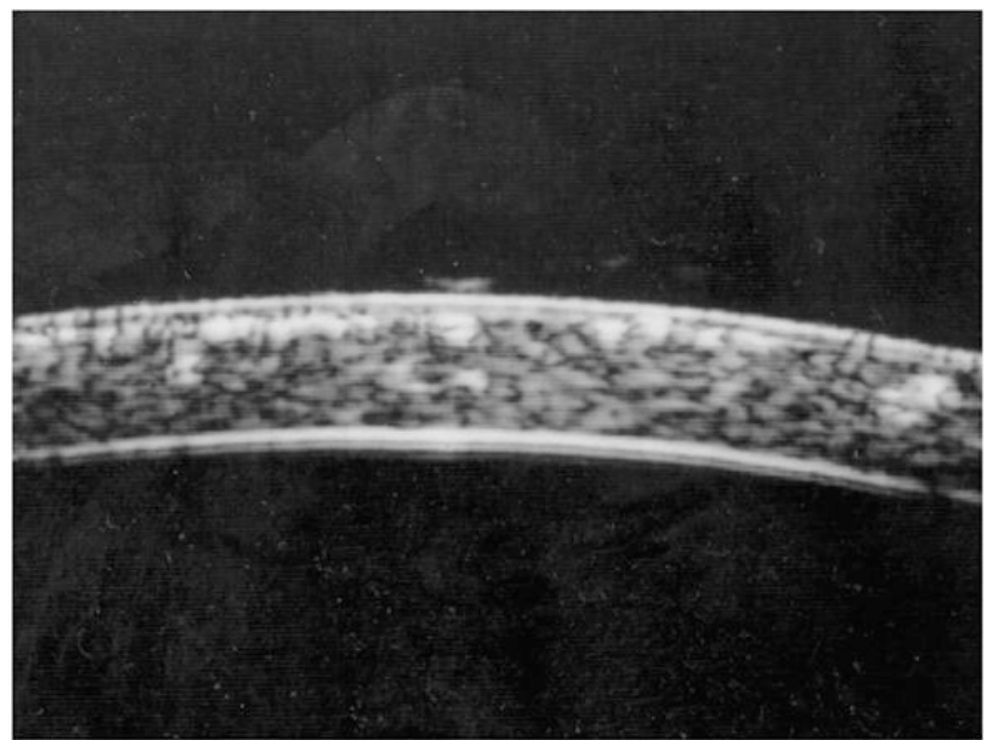

Figure 3.

Corneal dystrophy. UBM showing highly reflective hyaline granules in the superficial stroma of cornea with granular dystrophy. Reproduced with permission from : Pavlin CJ, Foster FS. Ultrasound Biomicroscopy of the Eye, Springer Verlag, New York 1994. 


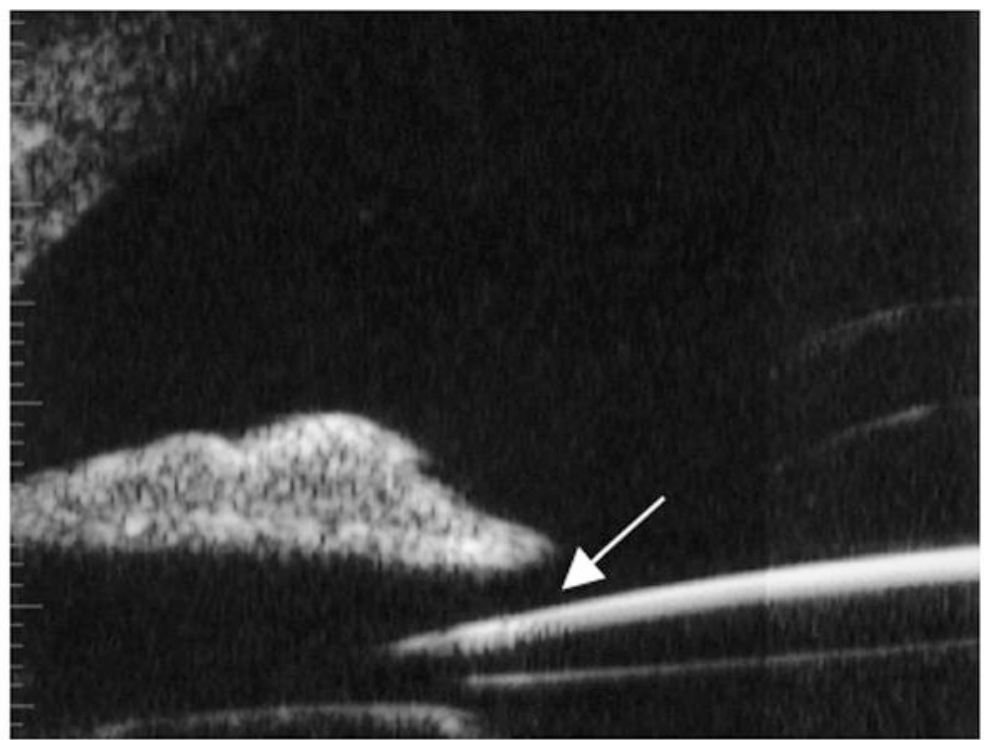

Figure 4.

Tilted PC IOL. Radial scan of the central iris and PC IOL shows a slight tilt off the horizontal axis indicting displacement of the PC IOL (arrow). 


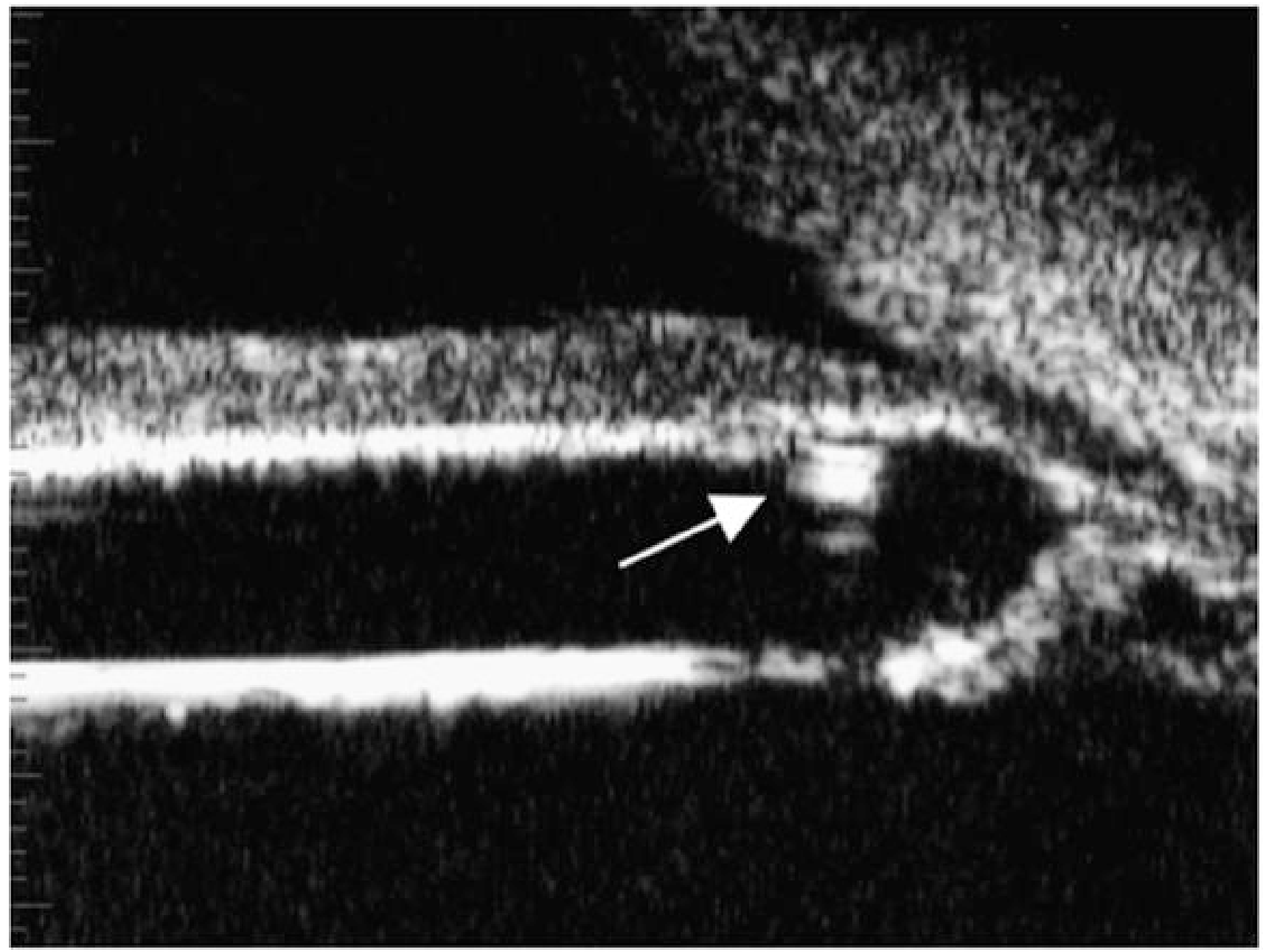

Figure 5.

Displaced PC IOL. Radial scan of the anterior chamber shows PC IOL displaced temporally with the haptic abutting the peripheral iris (arrow). 


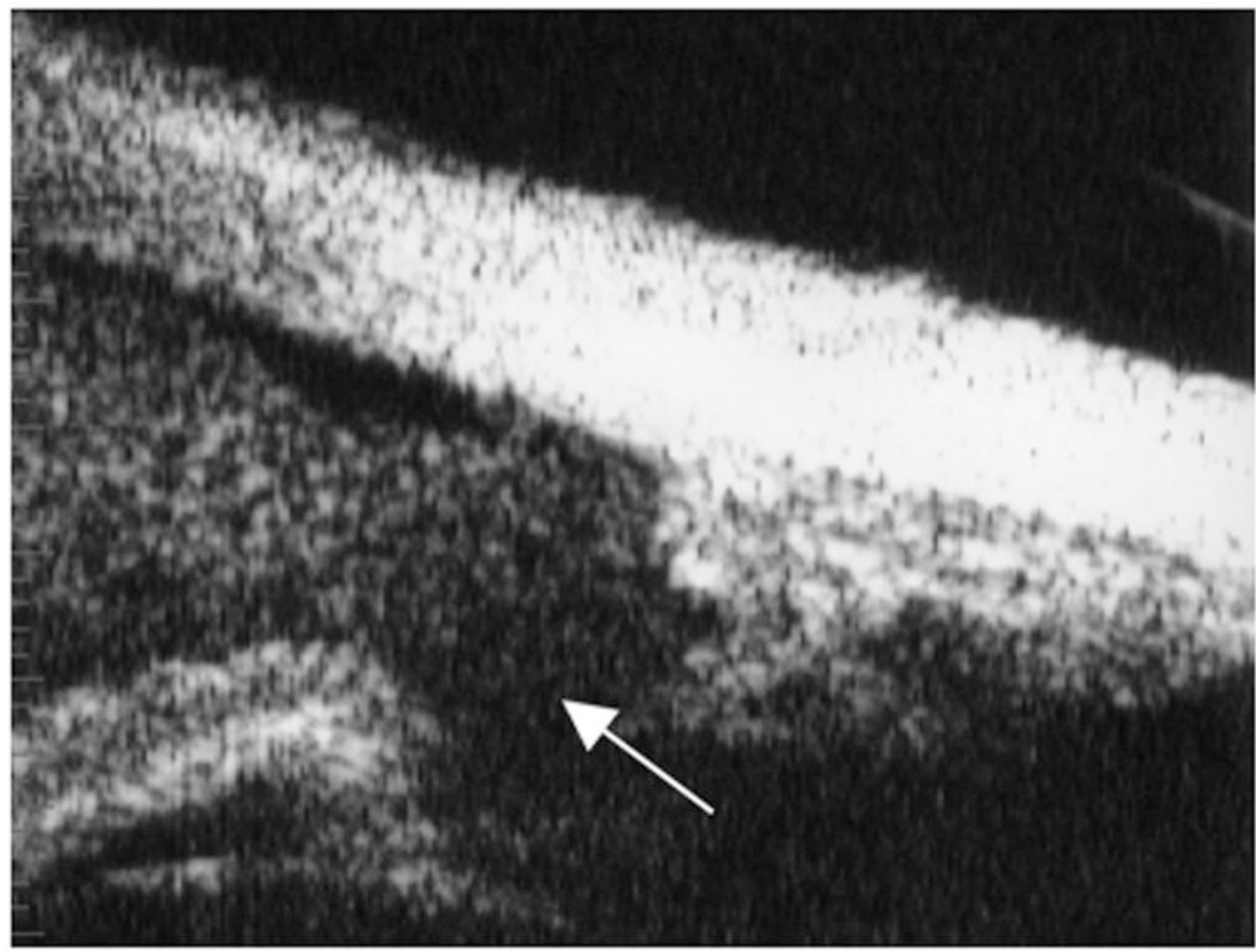

Figure 6.

Iridodialysis. Radial scan shows complete separation of the iris from the root (arrow). 

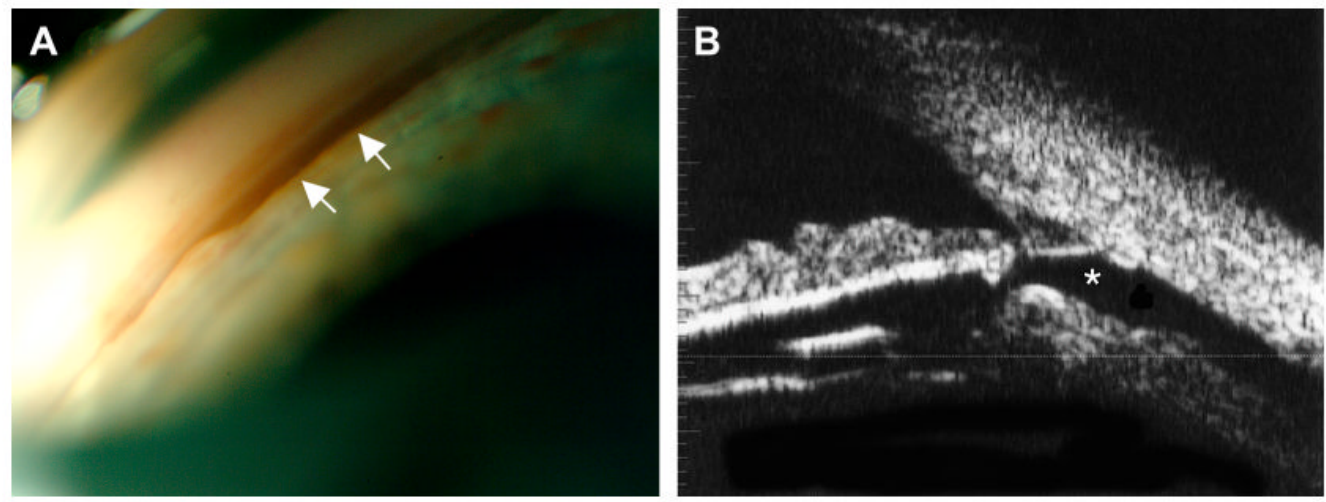

Figure 7.

Cylcodialysis. Goniophotograph showing cleft in the anterior chamber angle (A, arrows). Radial scan shows complete separation of the ciliary body from the scleral spur (B, asterix). 


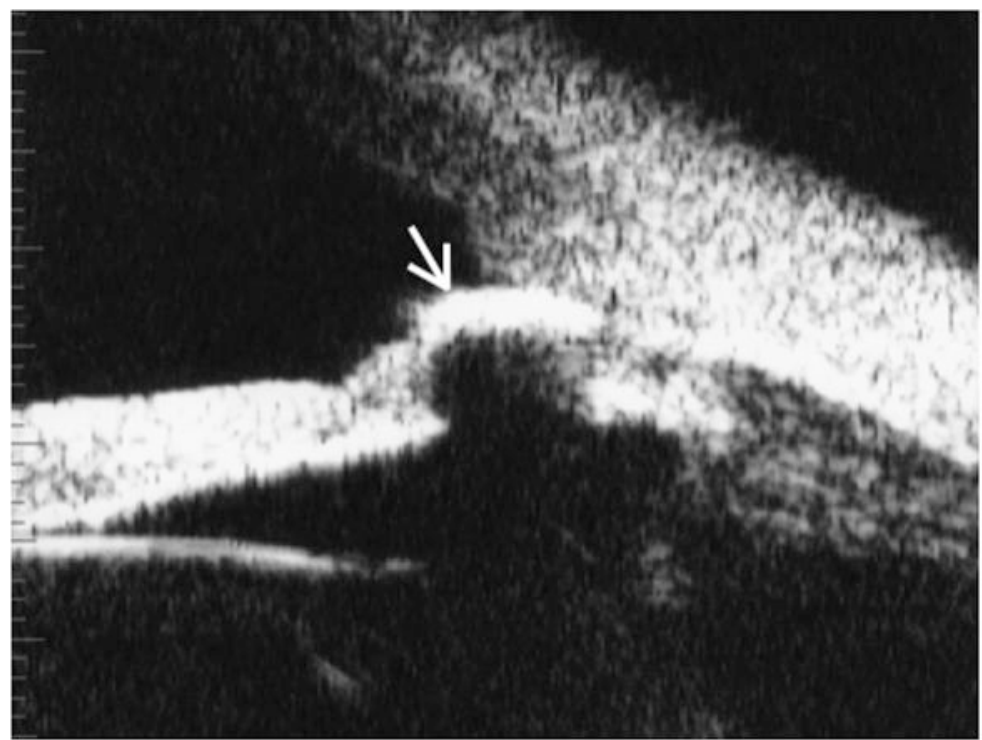

Figure 8.

Metallic intraocular foreign body. Radial scan shows an irregularly shaped, highly reflective foreign body in the anterior angle (arrow). Note the shadowing of the intraocular structures beneath the hyperechoic foreign body. 


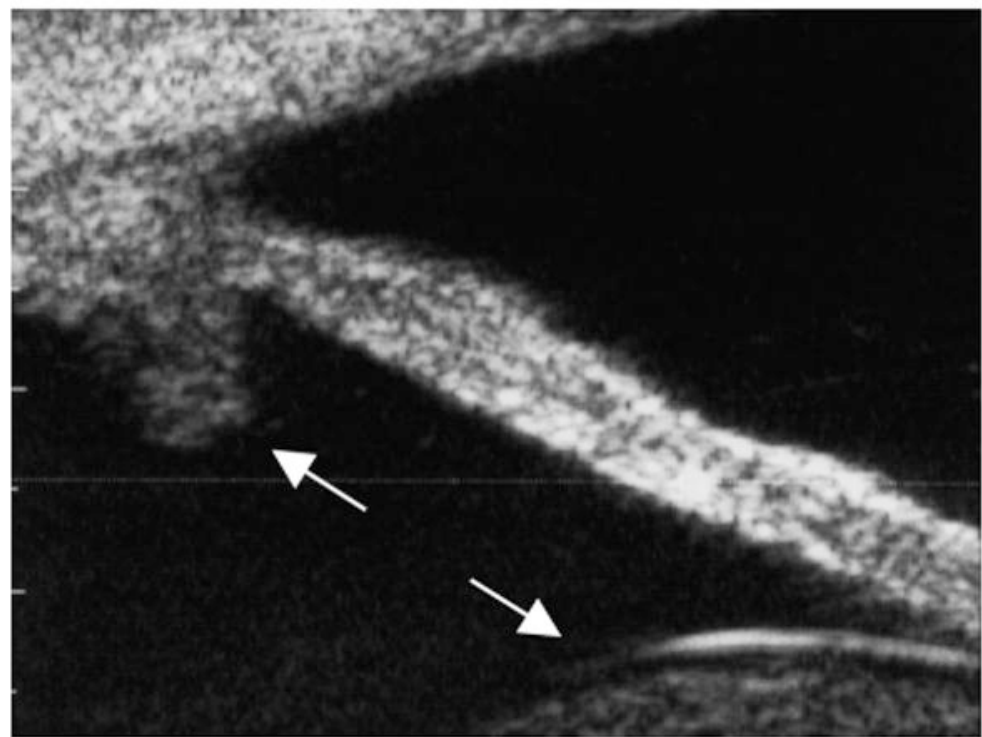

Figure 9.

Zonular Injury. Radial scan shows the absence of the zonule normally extending from the ciliary process (arrow) to the lens surface (arrow). (Image courtesy of Charles J. Pavlin MD). 


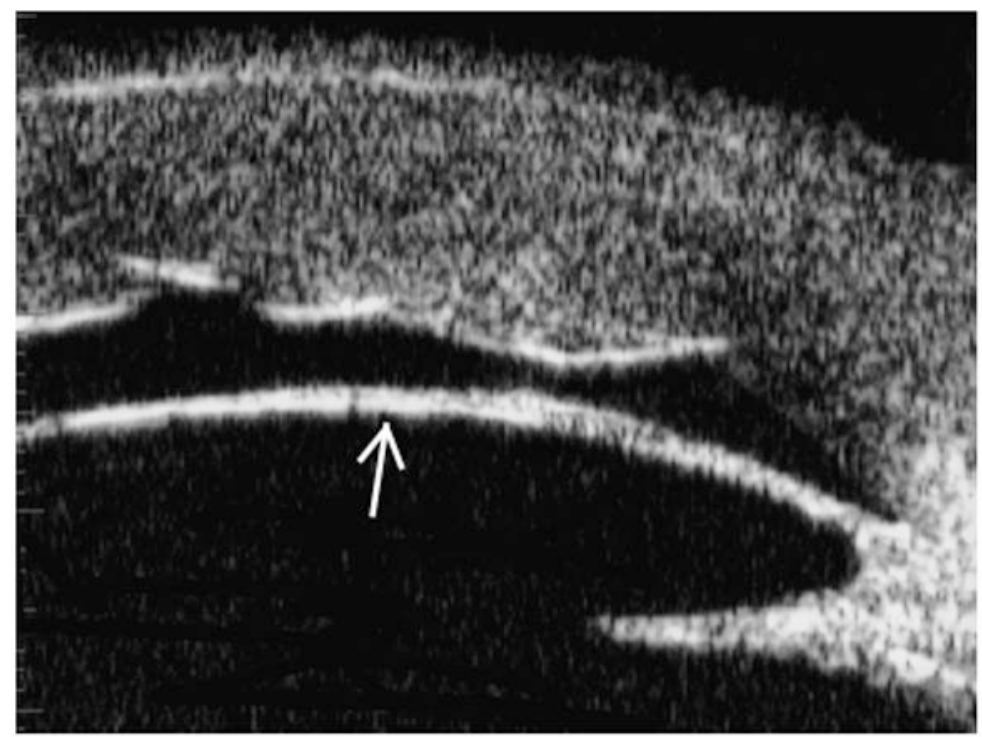

Figure 10.

Descemet's membrane detachment. Radial scan shows irregularly thickened cornea with a smooth, highly reflective detachment of Descemet's membrane (arrow). 